\title{
Entre machos e discretos: discursos, identidades homoeróticas masculinas e(m) aplicativos de relacionamento
}

Between Machos e discretos: discourse, male homoerotic identities in relationship app

\author{
Júlia Antônia Maués Corrêa ${ }^{1}$ \\ Instituto Federal de Educação, Ciência e Tecnologia do Pará - IFPA \\ juliamaues@gmail.com \\ Marcos da Silva Cruz ${ }^{2}$ \\ Instituto Federal de Educação, Ciência e Tecnologia do Pará - IFPA \\ marcozcrus.ifpa@gmail.com
}

RESUMO: A pós-modernidade e os aplicativos móveis enfatizaram a complexidade do processo de articulação de sentidos, identidades e poder, configurados, na situação do homoerotismo, pela imposição do deslocamento para os aplicativos de pegação. Nesse território, destacam-se os usuários defensores da masculinização da identidade homoerótica e promotores da discrição da feminilidade, definidos como machões e discretos, os quais, todavia, têm suas identidades reduzidas ao discurso homogêneo e hegemônico. Apoiados nos pressupostos da teoria queer (LOURO, 2001; BORBA, 2015; MOITA-LOPES, 2006) e da Análise Crítica do Discurso (CHOULIARACK; FAIRCLOUGH, 1999; FAIRCLOUGH, 2001), visamos à compreensão das identidades dos "machões e discretos" no aplicativo de relacionamento Grindr, problematizando as articulações das diferenças identitárias. Para tal procedimento, investigamos os usuários em Belém do Pará, analisando os perfis e as narrativas identitárias, com entrevistas por meio do bate-papo do aplicativo. Como resultados, a ideia de homogeneidade é efeito de um aparato heterossexista, o qual envolve a inscrição de valores difusos sobre masculinidade, feminilidade, papéis sexuais e performances públicas, inscrevendo os "machões e discretos" em um entrelugar definido pela debilidade performática e sua projeção no parceiro-em-potencial.

Palavras-chave: Masculinidade; Masculinização; Homoerotismo; Grindr; Performances.

\begin{abstract}
The post-modernity and the mobile apps emphasize the complexity of meanings, identities and power, configured, in the case of homoerotism, by the imposition of displacement for crush apps. In this territory, stand out some users who defend the masculinization of homoerotic identity and promote the discretion of feminility, the "machos e discretos", which are, however, reduced to homogeneous e hegemonic speech and identity. Supported by Queer theory assumptions (LOURO, 2001; BORBA, 2015; MOITA-LOPES, 2006) and Critical

\footnotetext{
${ }^{1}$ Doutora em Linguística Aplicada pela Universidade Estadual de Campinas (UNICAMP) e Professora Titular do curso de Letras-Língua Portuguesa no Instituto Federal de Educação, Ciência e Tecnologia do Pará (IFPA), campus Belém.

${ }^{2}$ Graduado em Letras, com habilitação em Língua Portuguesa pelo Instituto Federal de Educação, Ciência e Tecnologia do Pará (IFPA).
} 
Discourse Analysis (CHOULIARACK; FAIRCLOUGH, 1999; FAIRCLOUGH, 2001), we aim the comprehension of "machos e discretos" identity on Grindr, problematizing the articulation of identity differences. For this procedure, we investigate Grindr users in Belém, Pará, analyzing the profiles and the identity narratives, with interview through app chat. As results, the ideia of homogeneous is a effect of heterosexist display, which involve the subscription of diffuse values about masculinity, femininity, sex roles and public performances, writing in the "machos e discretos" in a between place defined by the performatic debility and its projection on potencial partner.

Keywords: Masculinity; Masculinization; Homoerotism; Grindr; Performances. 


\section{Introdução}

A pós-modernidade, por meio do processo de globalização, é caracterizada pela mudança na dinâmica comunicacional e interacional dos sujeitos, ampliando as formas de construção de conhecimentos, de culturas, de identidades e de formas de racionalidade (SANTOS, 2004; HALL, 2006). Dentre as mudanças, destacam-se a consolidação de um regime global de marginalização das diferenças sexuais e o deslocamento dos chamados "sujeitos dissidentes" (BORBA, 2015) por conta de suas sexualidades para interações on-line, motivados pelo paradigma heterossexista de imposição da heterossexualidade aparente. As interações on-line são conjecturadas, na virada do milênio, pela difusão de aplicativos de relacionamento, como territórios permitidos para desenvolvimento de relacionamentos afetivos e/ou amorosos.

A modificação das formas de construção de identidade homoerótica por meio de aplicativos de pegação é singularizada por conta de dois aspectos: de um lado, a latência de uma população de usuários distinguíveis pela defesa de uma identidade homoerótica masculinizada, próxima da heterossexualidade, e pela condenação da feminilidade, a qual definimos sob a expressão "machões e discretos"; de outro, um conjunto de usuários promotores da condenação de perfis heterossexistas. Todavia, no meio desse debate, pressupõe-se que a identidade dos "machões e discretos" é homogênea, caracterizável somente pela defesa da masculinidade masculinizada. Em sentido contrário, ancorados pela concepção de fragmentação identitária do sujeito pós-moderno (HALL, 2006), buscamos problematizar a noção, a priori, homogênea da identidade dos "machões e discretos", compreendendo os sentidos e condições mobilizados para construção do homoerotismo masculino de usuários do Grindr.

O realce das construções identitárias dos "machões e discretos" encontra-se ambientado no aplicativo de relacionamento Grindr. Este surgiu em 2008 por conta da insatisfação de seu criador, Joel Simkhal, com os sites de relacionamento vigentes à época, pois apresentavam lacunas ao desconsiderar os parceiros amorosos e/ou sexuais próximos aos usuários. Assim, em 2009, Simkhal disponibiliza o Grindr, iconoclasta em relação ao funcionamento por localização geográfica do usuário, permitindo encontrar parceiros-empotencial com rapidez e proximidade, dispostos em uma grade. No início, o aplicativo visava abranger todas as categorias dispostas no círculo LGBT, permitindo a interação e troca de informações, o que, com o passar do tempo, não foi concretizado. Na verdade, no decorrer da utilização, o aplicativo adquiriu certa especialização em torno dos sujeitos do sexo masculino, 
Júlia Antônia Maués Corrêa; Marcos da Silva Cruz. Entre machos e discretos: discursos, identidades homoeróticas masculinas $\mathrm{e}(\mathrm{m})$ aplicativos de relacionamento

concentrando, por conseguinte, a maior incidência dos discursos sobre masculinização do homoerotismo.

Anterior a incursão teórico-metodológico, convém distinguir duas expressões utilizadas no decorrer do texto: a diferença entre "sujeito homoerótico masculino" e "sujeito homoerótico masculinizado ou sujeito masculinizado". Em relação à primeira, concebemos a todos os sujeitos homoeróticos, considerando que os papéis sexuais não eliminam a masculinidade do indivíduo; sobre o segundo, referimo-nos a população-objeto da pesquisa como os sujeitos promotores da heterossexualidade aparente, que, ao vivenciarem a impostação da masculinização, tornam-se subservientes ao regime da heterossexualidade compulsória.

No ensejo de refletir sobre a identidade dos "machões e discretos", apresentamos, em primeiro lugar, a trajetória de construção do homoerotismo, da abjeção e do deslocamento para os aplicativos, pontuando a relação entre on-line e off-line e o papel do discurso heterossexista na formação da população de "machões e discretos". Em segundo lugar, sintetizamos algumas contribuições teóricas sobre o papel do discurso na construção das identidades de gênero e sexuais, destacando a teoria utilizada para análise dos discursos dos usuários do Grindr - a saber, a Análise Crítica do Discurso. Em seguida, analisamos as narrativas de dois informantes, discriminando os elementos que compõem a sexualidade homoerótica e seus condicionamentos. Por último, como considerações, apontamos as regularidades de sentido para a construção, as ambiguidades da identidade homoerótica masculinizada e enfatizamos a homogeneidade como efeito de um aparato heterossexista silenciado.

\section{O homoerotismo masculino (masculinizado): a construção da abjeção e o deslocamento dimensional}

O processo de (re)conhecimento do indivíduo como sujeito social perpassa por aspectos históricos e culturais de uma comunidade social interactante, articulando, nas palavras de Hall (2006, p. 9), diferentes "paisagens culturais de classe, gênero, sexualidade, etnia, raça e nacionalidade". Contudo, essa articulação amplia-se a reflexões recentes, pois, em períodos anteriores, as identidades foram compreendidas sob duas óticas: a primeira, iluminista, na qual o sujeito nascia, crescia e morria com características e comportamentos imutáveis, validando os conhecimentos biológicos e os pressupostos religiosos; a segunda, 
Júlia Antônia Maués Corrêa; Marcos da Silva Cruz. Entre machos e discretos: discursos, identidades homoeróticas masculinas $\mathrm{e}(\mathrm{m})$ aplicativos de relacionamento

sociológica, acrescenta a interpretação de identidade como uma articulação subjetiva (particular) composta a partir de um ordenamento social (objetivo). Somente com a perspectiva pós-moderna (HALL, 2006), pautada no questionamento da unidade das identidades, foi possível desvelar a complexidade e movência identitária por diferentes práticas sociais.

As perspectivas do iluminismo e da sociologia influenciaram, no decorrer dos séculos XVII ao XIX, uma concepção de identidades muito restrita, o que direcionava uma parcela social às margens, pois não cumpririam os requisitos necessários de uma imagem ideal. Bourdieu (2012), ao analisar a construção social da masculinidade, constata um sistema de causalidade circular pelo qual os critérios de sexo, gênero e sexualidade são manufaturados discursivos, isto é, representam categorizações para a atribuição de sentidos sobre os sujeitos sociais. Em decorrência disso, um grupo social dominante utiliza destes parâmetros para impor formas de identificação e comportamento sociais e, a partir da repetição, categorizar os papéis sociais dos sujeitos entre aqueles que cumprem as imposições e os dissidentes à norma.

Ao considerar o agrupamento dos dissidentes à norma sob o signo de "homossexuais", Louro (2001) debruça-se sobre os percursos de sentido construídos sobre a homossexualidade e os sujeitos adjetivados como tal. Em sua síntese, a autora distingue dois momentos representativos para a compreensão das sexualidades: o primeiro, de origem religiosa no século XIX, visualizava a dissidência como sodomia, exercida por sujeitos representativos do pecado da carne, e uma forma de desvio de caráter, justificativas, à época, para condenação dos sujeitos. Com validade unívoca até $1970^{3}$, o discurso religioso é abalado por conta de organizações de sujeitos homoeróticos reivindicando condições cidadãs de vida, o que motivou a rearticulação dos modos de imposição da norma.

No segundo momento, a partir da década de 70, descreve Louro (2001), os discursos institucionais autorizados a caracterizar a homossexualidade restringiam-se ao âmbito médico e jurídico, pois, respectivamente, compreendiam a dissidência como patologia psíquica, passível de cura, e desvio de caráter. Pela mudança de instituições, a homossexualidade foi reprimida de forma violenta pelo Estado, como ilustra Segdwick (2007) sobre o caso de Stonewall $^{4}$ e uma série e locais frequentados por sujeitos homoeróticos onde a polícia

\footnotetext{
${ }^{3}$ Embora essa delimitação temporal, a concepção religiosa não deixou de se vinculada na sociedade. Ao contrário, mantém sua participação, contudo, compartilhada com outras instâncias sociais.

${ }^{4}$ De modo geral, o movimento de Stonewall foi uma resposta ao conjunto de procedimentos repressores cometidos pela polícia dos Estados Unidos, desencadeadores de uma série de manifestações contra os discursivos e ações homogeneizantes da sexualidade.
} 
espancava os frequentadores ${ }^{5}$, ou ainda, de modo mais ameno, as políticas restritivas às saunas, como apresentou Perlongher (1987). Esses são os primeiros eventos que contribuem para o deslocamento compulsório dos homoeróticos de espaços públicos, pelo receio a vida e pelas restrições sociais geradas pela rotulação imposta ao frequentar determinados locais.

A visibilização da aids $^{6}$, na década de 1980, representou, na visão de Miskolci (2017), um terceiro momento para a articulação política dos sujeitos homoeróticos, pois, de um lado, os discursos médico e jurídico condenavam a dissidência e defendiam a prática higienista e, de outro, os sujeitos dissidentes buscavam evidenciar a ausência de perigo social. Todavia, o aparato discursivo hegemônico prevaleceu, em uma configuração de tolerância a dissidência, desenvolvendo estratégias de controle da identidade e dos comportamentos públicos e privados. Para isso, difundiu uma série de valores subsidiados pelo eixo sexo-gênerosexualidade, impondo um eixo de inteligibilidade no qual o sexo biológico define o gênero da criança $^{7}$ e, por extensão, os comportamentos e desejos sexuais ao longo da vida.

Mais recentemente, como reflexo das políticas de higienização e da insurgência da web 2.0, os sujeitos homoeróticos deslocam-se para os aplicativos de relacionamento como forma de preservar a integridade simbólica e física e, ao mesmo tempo, continuar suas interações por meio da produção de conteúdos. Nesse sentido, identifica Miskolci (2017), surgem diferentes aplicativos voltados para os diferentes segmentos ${ }^{8}$ do grupo LGBTQI+, dentre os quais, para o público masculino ${ }^{9}$, o Grindr. Segundo informações do site oficial,

\footnotetext{
${ }^{5} \mathrm{O}$ caso de Alan Turing também é emblemático na medida em que envolve a imposição de escolhas de performance para viver em sociedade e a alteração da subjetividade. Para maiores detalhes, ver MISKOLCI, R. Desejos digitais: uma análise sociológica da busca por parceiro on-line. Belo Horizonte, MG: Autêntica Editora, 2017.

${ }^{6}$ A utilização do termo aids em letras minúsculas é uma forma de tratamento e designação do indivíduos aidéticos diferente do modus operandi da década de 80 , pois, à época, a aids foi construída como forma de estigmatização, implicando em uma onda de mortes, seja pela ausência de tratamento ou pelas posturas reacionárias da população. Portanto, o uso do termo em letras maiúsculas (AIDS) representou uma estratégia discursiva, de subversão do sentido da doença, como forma de manipulação social para condenação e higienização dos sujeitos homoeróticos das/nas relações públicas.

${ }^{7}$ A utilização do termo "criança" justifica-se a partir das exemplificações de Butler (2003), pois, segundo a pesquisadora, desde o momento do nascimento, talvez na sala de parto, ocorre uma série de práticas sociais que confluem para uma definição categorial entre menino e menina, acarretando o desenvolvimento de múltiplas expectativas em torno da identidade de gênero e do desejo sexual.

8 A título de esclarecimento, o desenvolvimento de aplicativos é resultado da "política de identidade", compreendida por Mignolo (2008, p. 289) como processo que considera como relevante todas as características das identidades, em seu espectro, moldado e contextualizado em realidades locais específicas. Por outro, o processo de "política de identidade" compreende as identidades na ótica da essencialidade, ao priorizar características em detrimento de outras, enfatizando superioridade dos sujeitos que hierarquizam os graus de importância das diferenças.

${ }^{9}$ Embora o Grindr tenha sido, em sua fase inicial, projetado para quaisquer sujeitos homoeróticos, a configuração social marcada pela "política de identitária" (MIGNOLO, 2008), interna ao grupo LGBTQ, acabou por segmentar os usos de determinados aplicativos.
} 
Desde 2009, o Grindr cresce rapidamente como a maior rede social para gays, bissexuais, transexuais e pessoas queer, com aproximadamente três milhões de usuários por dia em cada país do mundo. Nós estamos em todo lugar, e o nosso objetivo é continuar expandindo nossa marca. Mais do que um espaço digital para conhecer, o Grindr também exerce iniciativas de sucesso ao almejar a solução dos problemas $L G B T Q$, incluindo igualdade social, justiça, saúde e outros (grifo nosso; texto da apresentação da importância do aplicativo em sua página oficial ${ }^{10}$ ).

Nesse espaço de interação, percebe-se a intersecção de problemas sociais, os quais convergem para as práticas interacionais dos usuários, dificuldades motivadas por uma estrutura social heterossexista, tornando latente a infiltração dos valores da heterossexualidade compulsória no discurso de uma população de usuários chamados "machões e discretos", caracterizados pela condenação da feminilidade e a defesa da discrição das relações homoeróticas, bem como a ênfase em comportamentos masculinizados, em troca de acessibilidades sociais e cidadania.

A interação e a formação da identidade no âmbito do aplicativo, defende Miskolci (2017), não se restringe as práticas on-line, pois, desde o surgimento ao objetivo da interação, prescindem do off-line, fazendo-o concluir que há um continuum entre on-line e off-line na construção de identidade homoeróticas masculinas masculinizadas. Porém, o exercício analítico sobre a funcionalidade do regime continuado ainda é debilitado no ramo dos estudos linguísticos, pois, muito embora a linguagem ocupe papel central na consolidação das identidades, ainda implica certa nebulosidade acerca dos sentidos, funções sociais de determinadas construções identitárias.

De modo geral, o processo de construção do homoerotismo masculino é marcado pelo condicionamento de discursos institucionalizados - religioso, médico e jurídico, os quais constroem uma imagem unilateral das sexualidades e conduzem a comportamentos destrutivos a partir de um eixo de inteligibilidade. Em primeiro plano, a violência simbólica ocorre entre a hegemonia heterossexual e os grupos homoeróticos e, em decorrência das possibilidades de acessibilidade, entre os sujeitos homoeróticos masculinos sob o critério da heterossexualidade aparente. Essa configuração gera conflitos que envolvem a configuração sócio-histórica e identidade, experiências e desejos amorosos e/ou sexuais, conformando uma trama complexa na qual a identidade dos "machões" ainda é vista sobre a ótica iluminista.

\footnotetext{
${ }^{10}$ Resgatamos o posicionamento dos responsáveis pelo aplicativo, disponível na aba "sobre" no site oficial do Grindr (<https://www.grindr.com/br/about>), como forma de ratificar o reconhecimento do papel e dos problemas sociais que permeiam o aplicativo, da incidência da masculinização na construção das identidades dos "machões e discretos" e a elucidação da natureza do aplicativo como efeito das pressões normativas promotoras do deslocamento dimensional.
} 
Com esse pano de fundo contextual, teórico e metodológico, problematizamos a composição da identidade dos "machões e discretos", ao questionar os sentidos sobre masculinidade, discrição e feminilidade mobilizados para caracterização da masculinização, a localização do sujeito ao calcular valores sociais dissidentes e hegemônicos, o papel do aplicativo e a relação dos condicionantes entre off-line e on-line para estabilização da identidade.

\section{A abjeção do homoerotismo, a masculinização homoerótica e os horizontes identitários: a centralidade do discurso}

O próprio desenvolvimento das ideias sobre identidades sexuais, abjeção e o deslocamento multidimensional (on-line e off-line) dos sujeitos homoeróticos masculinos é atravessado constantemente pela noção de discurso, demandando a elucidação das potencialidades do discurso na construção de identidades homoeróticas. Foucault (1988) dedicou-se ao estudo das relações entre as ordens de discurso e as construções da sexualidade, argumentando que o discurso era um dos instrumentos para quantificar o valor simbólico das experiências sexuais, a depender do momento histórico e do cenário cultural. Todavia, esse procedimento restringia-se a autoridades específicas que, no caso dos séculos XVIII a XX, eram os membros da igreja, e, a posteriori, os médicos psicanalistas. Como ponto em comum, ambas as autoridades utilizavam a estratégia de confissão ${ }^{11}$ a fim de construir conhecimento sobre a ideia de homossexualidade, embora as epistemes desenvolvidas fossem visões unilaterais, que conduziam ora a percepção de corrupção da alma e do caráter ou a anomalia fisiológica ${ }^{12}$.

Como leitora de Foucault (1988) e de Austin (1990), Butler (2003) amplia a noção de manufaturado discursivo à concepção de gênero, pois, segundo ela, as categorias de gênero também são uma forma de construção social da realidade e dos corpos. A capacidade de construção conduz Butler a compreender, sob a lente de Austin, o discurso e as identidades de

\footnotetext{
${ }^{11}$ Ainda hoje, percebe-se a influência do pressuposto de "assumir-se" como necessário para validação da homossexualidade. Spargo (2017) relata que, no contexto político, alguns representantes foram expostos coercitivamente como homossexuais, isto é, foram "tirados do armário" compulsoriamente, atitude esta resultante de uma tendência social marcada pela "luta pela visibilidade das minorias e pelo combate á homofobia" (p. 10). Contudo, o que ocorre é uma dissimulação da aceitação, pois a confissão funciona como instrumento para justificar a reprovação e marginalização dos sujeitos.

${ }^{12}$ Spargo (2017) acrescenta que, na década de 1970, o discurso da psicanálise era atravessado pelos pressupostos econômicos ao sintetizarem a sexualidade, a procriação e a fertilidade como dimensões para produção de mão de obra.
} 
gênero e sexual como performativas, elaboradas a partir de certos locutores, com certos conhecimentos e de perspectivas regentes da vida cotidiana. Contudo, a performatividade é um processo embebido pela noção de linearidade entre sexo, gênero e sexualidade, na qual dizer "é uma menina" resgata o pressuposto de uma vagina como órgão sexual e impõe comportamentos afeminados e o interesse amoroso/sexual pelo sexo oposto (homem), compatível com a identidade essencializada e homogênea do iluminismo proposta por Hall (2006).

$\mathrm{Na}$ esteira da concepção de linearidade, as identidades configuram-se por meio de um sistema de imposições, realizáveis mediantes performances ${ }^{13}$, ou seja, comportamentos que indexam para categorias dicotômicas (homem/mulher; heterossexual/homossexual). Essas performances são, ambiguamente, fonte do conhecimento sobre a sexualidade e parâmetro para distinção categorial e de acessibilidades sociais. Porém, na mesma medida, aponta Butler (2003), há a estilização das performances como práticas situadas através das quais as identidades rompem com algum dos componentes da linearidade, convergindo para um espaço que, conforme Borba (2015), é marcado por processos de construção, de negociação e de estruturação das identidades por meio do discurso, permeados nos conjunto social da heterossexualidade e localizando os contextos sociolinguísticos e as ideologias norteadoras das práticas identitárias e de atribuição de sentido a elas (em caráter de normalidade ou anormalidade).

Mediante a complexidade das "paisagens culturais" (HALL, 2006), de negociação entre linearidade e da estilização, o paradigma heterossexual realiza uma rearticulação estratégica sobre a construção da identidade homoerótica masculina, difundindo a necessidade de preservação da masculinidade aparente, similar a heterossexualidade, em práticas sociais públicas. Essa modificação significa, na compreensão de Bourdieu (2012), o resgate da masculinidade como nobreza, pois

[...)] não seria exagero comparar a masculinidade a uma nobreza. Para convencernos disso, basta observar a lógica, bem conhecida dos cabilas do Double standard, como dizem os anglo-saxões, que instaura uma dissimetria radical na avaliação das atividades masculinas e femininas. Além do fato de que o homem não pode, sem derrogação, rebaixar-se a realizar certas tarefas socialmente designadas como inferiores (entre outras razões porque está incluída a ideia de que ele possa realizá-

\footnotetext{
${ }^{13}$ Lewis (2018) elucida, de modo objetivo, a distinção entre performance e performatividade na obra de Butler, pontuando como performance todo ato discursivo-corporal, constituinte de um processo de normas e papéis sociais e, do outro lado, a performatividade como o processo de repetição de performances para normatização ou subversão dos comportamentos de papéis sociais. Logo, a relação entre os dois conceitos configura-se pela suplementariedade, pois a performance só ocorre mediante o aproveitamento da performatividade e esta depende das performances para instaurar-se.
} 
Júlia Antônia Maués Corrêa; Marcos da Silva Cruz. Entre machos e discretos: discursos, identidades homoeróticas masculinas $\mathrm{e}(\mathrm{m})$ aplicativos de relacionamento

las), as mesmas tarefas podem ser nobres e difíceis quando são realizadas por homens, ou insignificantes e imperceptíveis, fáceis e fúteis, quando realizadas por mulheres, como nos faz lembrar a diferença entre um cozinheiro e uma cozinheira, entre o costureiro e a costureira (p.75).

O rompimento estilizado das performances lineares inscreve-se na lógica do Double standart, na qual as atitudes feminilizadas realizadas por sujeitos homoerotismo masculinos adquirem a desvalorização simbólica se comparadas com as performances masculinizadas. Essa compressão realça o deslocamento das performances de um parâmetro de essência, seja na vida pública ou privada, para a necessidade da aparência como forma de preservação da ordem social. Logo, é preciso, por parte do homoerótico masculino, atuar como heterossexual nas situações públicas como metodologia promotora das acessibilidades sociais e da dignificação identitária.

No âmbito dos estudos linguísticos, Moita-Lopes (2002), ancorado nas percepções de Foucault e Butler, ratifica a função do discurso como ação social, como performativo, pois cria o mundo e, sobretudo, produz identidades e lugares socialmente distintos. Assim como Foucault, Moita-Lopes (2002) identifica os componentes necessários para a construção de uma ordem social, de comportamento, distinguindo-os em três instâncias: o sujeito e/ou instituição; o discurso e sua autoridade; e o conhecimento (re)produzido. Ao considerar o discurso psicanalítico, a psicanálise e/ou o psicanalista atuam como sujeito que, por meio dos procedimentos de coletas, análise e comparação dos comportamentos, vestimentas e etc. produziam enunciados caracterizadores, projetando a identidade pública do sujeito homoerótico, circunscrevem as formas de identificação e delimitam os lugares sociais de gays/lésbicas.

Ao constatar o problema sobre os procedimentos de análise social, os quais também envolvem a construção de identidades homoeróticas, Fairclough e Chouliaraki (1999) e Fairclough $(2001 ; 2012)$ identificam, no paradigma analítico, os equívocos empreendidos pelos estudos linguísticos ao privilegiarem ora o nível social ora o linguístico, distanciando de uma análise balanceada sobre a complexidade dos dois níveis e suas articulações. Em sentido contrário, atualizando as contribuições de Foucault ${ }^{14}$, os autores propõem uma Análise Crítica do Discurso (ACD) como método para a pesquisa social, na qual o discurso ocupa posição central ao garantir a ação no mundo e as representações sociais dos sujeitos, englobando três dimensões das práticas sociais, conforme a Imagem 1.

\footnotetext{
${ }^{14} \mathrm{O}$ discurso como construtor das identidades e posições sociais; os elementos constituintes das ordens de discurso; e o papel da historicidade na construção de sentidos, objetos e conceitos.
} 
Imagem 1 - Modelo tridimensional do discurso

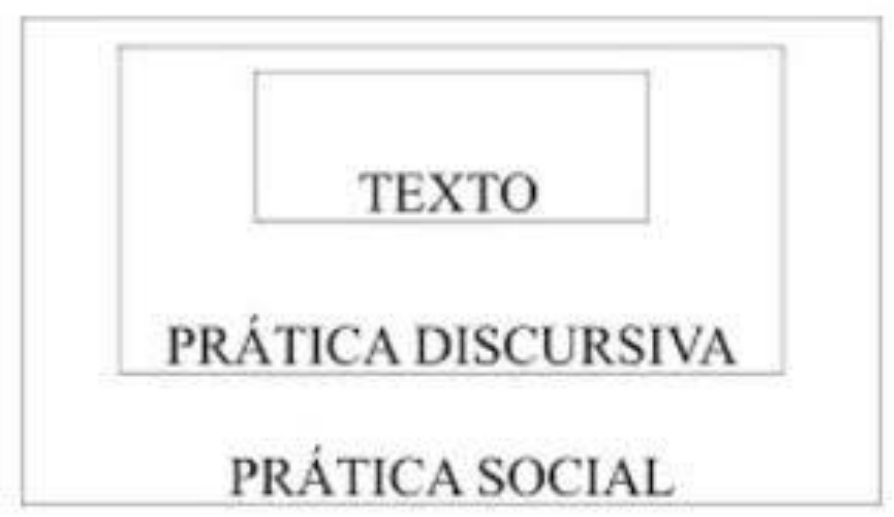

Fonte: Fairclough (2001).

$\mathrm{Na}$ dimensão da prática social está disposta, em primeiro lugar, a prática política, compreendida como a forma pela qual o discurso busca o estabelecimento, a manutenção e a transformação das relações de poder e das representações das entidades coletivas (como os sujeitos homoeróticos). Em segundo, a prática ideológica, ou seja, o subsídio cognitivo (VAN DIJK, 2008) e objetivo responsável pela constituição, naturalização e transformação dos significados do mundo, dos objetos e das identidades a partir das relações de poder. Como dimensão subsequente, da prática discursiva, destaca-se a ordem do discurso de Foucault, as características linguístico-discursivas do evento comunicativo, articulando produção, distribuição e consumo, os quais são atravessados pela força, coerência e intertextualidade dos enunciados. Por último, a dimensão textual abrange desde a mínima unidade lexical, o vocabulário, perpassando pela gramática, pela coesão e encerra na estrutura textual.

De modo geral, o acoplamento entre discurso e as formas de construção de identidades hegemônicas e marginalizadas, sob o critério da homogeneidade, conduz ao questionamento sobre a ideia de unidade das identidades dos "machões e discretos" difundida em aplicativos de relacionamento. A esse propósito nos dirigimos com base nas sinalizações da Análise Crítica do Discurso.

\section{Constructos analíticos e procedimentos metodológicos}

Baseando-se no princípio dialógico da linguagem (VOLOSHINOV [BAKHTIN], 2018), os procedimentos de análise dos discursos dos usuários do Grindr conhecidos como heteronormativos, e aqui chamados de sujeitos homoeróticos masculinizados, precede da elucidação de uma série de investimentos para a entrada do aplicativo, seleção dos perfis e 
geração dos dados. Sobre a forma de entrada, os apontamentos de Miskolci (2017) sobre a aproximação naturalizada do sujeito pesquisador-usuário foram norteadores para a criação de um perfil no qual ocorreu a identificação do pesquisador e sinalização do objetivo no $\operatorname{aplicativo~}^{15}$.

Pelo princípio da articulação e sobreposição das diferenças (HALL, 2006) em uma análise situada $^{16}$ (BORBA, 2015) e o funcionamento do aplicativo por sistema de GPS, selecionamos como cenário off-line o bairro da Cabanagem, periferia da cidade de Belém do Pará. A justificativa para seleção do bairro ocorreu pela necessidade de verificação da natureza relacional das dimensões, pois os eventos ocorridos no ambiente off-line, aparentemente desconectados, repercutem nas interações e discursos difundidos pelos usuários no âmbito do aplicativo, como indica a trajetória histórica de condução coercitiva da população homoerótica.

Definimos os critérios de seleção a partir dos seguintes parâmetros: (i) selecionamos apenas os perfis que, simultaneamente, apresentaram textos no espaço de descrição pessoal e que se enquadraram nas categorias de pertencimento identitário fornecidas pelo aplicativo; (ii) restringimos os perfis que, no espaço de descrição pessoal, indicavam termos semelhantes, análogos ou antagônicos à masculinidade aliados a discrição; (iii) elegemos, pela delimitação geográfica, os perfis com, no máximo, um quilômetro de distância da referência estabelecida (Rua Henrique Dias, em frente à delegacia do bairro).

Perante a seleção, procedemos à geração de dados em dois planos interdependentes e complementares. Sobre o primeiro, observamos as categorias de identificação pessoais fornecidas (de pertencimento social, posição sexual - ativo, passivo e versátil -, altura, peso e porte físico) pelo aplicativo e o texto/discurso inscrito na área de descrição pessoal. Somado a isso, convidamos os usuários selecionados para uma entrevista por meio do bate-papo do aplicativo, dos quais quatro responderam a entrevista semi-estruturada. A composição deste instrumento baseou-se na proposta metodológica de Santos Filho (2015), encontrada em sua tese de doutoramento, a saber: Quanto a ter performances masculinas: você se enquadra como masculino ou afeminado? O que o torna masculino ou afeminado? Em relação a ser discreto: você se enquadra nessa prática? Quais atitudes (não) o enquadram nesse perfil? Sobre a

\footnotetext{
${ }^{15}$ Importante destacar que, em primeira tentativa, sem a sinalização do objetivo de pesquisa, os usuários encaram a proposta de pesquisa no aplicativo como um procedimento jocoso, passível a dubialidade sobre os interesses do pesquisados ao realizar a comunicação.

${ }^{16}$ Nesse sentido, outra diferença significante circunda o processo formativo dos bairros na cidade de Belém, caracterizado, conforme Trindade (2000), pela distribuição desigual dos espaços sociais mediante o poder financeiro dos sujeitos, pela instalação das fronteiras urbano-imobiliárias (TRINDADE, 2001), pela valorização do corpo periférico como objeto da mais-valia e, sobretudo, pela condenação e apagamento das práticas sociais, culturais e políticas dos sujeitos dissidentes a linearidade de gênero (REIS, 2015).
} 
exigência dos usuários para que você seja masculino (macho) e discreto: isso dificulta ou facilita a interação com os outros usuários? Como você lida com isso?

Todos os procedimentos (de entrada, definição dos parâmetros, seleção dos usuários e entrevistas) ocorreram no período entre janeiro e dezembro de 2018, sendo as entrevistas desenvolvidas no excerto temporal de 09 e 15 de dezembro de 2018, com conversas de duração média de 25 minutos. Com a elucidação dos procedimentos metodológicos e suas referencias analíticas, passamos para análise dos discursos inscritos pelos sujeitos masculinizados. Em decorrência da extensão do gênero, selecionamos dois informantes representativos ("Cafajeste" e "Gui a fim”) para análise, o que ilustra os dados completos da pesquisa. Para efeito de sistematização, a análise dos usuários desenvolver-se-á mediante os dois planos complementares, do discurso do perfil e da entrevista, identificando os sentidos sobre a masculinidade e a masculinização, pontuando-as por meio das categorias da Análise Crítica do Discurso. Por último, as falas dos informantes serão diferenciadas das observações dos pesquisadores pelo uso de itálico e aspas.

\section{Cafajeste}

No nível textual, destacamos a sinalização do informante sobre sua subjetividade e corporalidade, ao afirmar-se como homem, de etnia latina, solteiro e que busca encontros casuais, amigos, contatos e relacionamentos. Contudo, pelas categorias do aplicativo, indexicaliza os traços da masculinidade, enfatizando o porte físico como "parrudo" e "bem gordinho" na área de descrição pessoal. Os elementos textuais, em primeira mão, indicam o reconhecimento do informante sobre a existência de padrões estético-corporais para a masculinidade, pois um corpo másculo representa um tipo de refúgio nas relações públicas, ao reproduzir performances, próximas da heterossexualidade aparente.

Embora o caráter impositivo de totalidade, as performances são cumpridas parcialmente pelo usuário, pois este reconhece que "se você não curte um cara bem gordinho, nem venha", sinalizando a ambiguidade de efetivação da linearidade aparente ao tangenciar o eixo imagético masculinizante. Como forma de balanceamento, o usuário utiliza o advérbio "bem" acrescido da flexão em diminutivo do adjetivo em "gordinho", como formas de amenização do rompimento do paradigma identitário da imperatividade masculinizante. Outra estratégia remete a inscrição de "Cafajeste" como termo "versátil" para esclarecer aos 
parceiros-em-potencial sua disponibilidade em relações amorosas e/ou sexuais em papéis sexuais distintos (ativo e passivo).

Sob a lente de Hall (2006), a performance de equiparação dos componentes identitários evidencia dois processos característicos da pós-modernidade: a constante articulação das diferenças identitárias a depender da prática social, de um lado, e a problemática da efetivação completa das diferenças frente um protótipo imagético, ocasionando tangenciamento. Além disso, acerca da versatilidade sexual, o princípio das masculinização pública é resgatado na medida em que o desempenho sexual configura-se como uma prática particular e, ao mesmo tempo, insere o informante em um quadro desregrado sobre a distinção de papéis sexuais e a manifestação identitária pública. Ao nivelar as ações em torno da heterossexualidade aparente, as performances públicas do usuário devem forjar somente o desempenho sexual enquanto ativo, pois os sujeitos ao interagirem pressupõem a atração pelo sexo oposto.

Dito de outro modo, a interpretação do usuário enfatiza a "naturalidade" da masculinização correlacionada ao papel sexual de ativo e as restrições performativas públicas de efeminamento. Nesse sentido, nas relações públicas, realiza-se a masculinidade, a agência sexual e a constituição da heterossexualidade aparente, e, nas relações privadas, pode haver a manifestação de feminilidade, correlacionada a passividade sexual. Portanto, no caso da versatilidade, o cálculo das performances é também enfatizado na medida em que é preciso regular as performances proporcionais ao espaço de interação.

Por meio do nível gramatical, a identidade de um parceiro-em-potencial é definida quando "Cafajeste" descreve que "quanto mais masculino for, melhor". A equação semântica construída sobre os termos "mais" e "melhor" circunscritos a ideia de masculino, além de revelarem o pressuposto da linearidade de gênero, descortinam um sistema singular de categorização da masculinidade, em um sistema gradual, oscilante de manifestação da masculinização, pelo qual a possibilidade de relacionamento é mensurada. Em conjunto, a satisfatoriedade de Cafajeste sobre a qualidade do relacionamento fundamenta-se na estabilidade da masculinização, em que o maior nível de satisfatoriedade corresponde ao maior nível de masculinização, inscrições oscilantes entre o masculino e o feminino, entre público e privado. Isso corrobora a interpretação acerca da necessidade do cálculo performativo entre interações públicas ou privadas.

Mediante o processo de alteridade (BAHKTIN, 2018) para inscrição das identidades sexuais (SEDWICK, 2007), os fundamentos da inscrição da masculinidade delineiam-se a partir da ideia de feminilidade, sendo sua irrealização quando o indivíduo "te(m) sobrancelhas 
naturais [...] Tudo natural". Conforme Miskolci (2017), esses sentidos revelam, em primeiro lugar, os parâmetros corporais sobre masculinidade - a sobrancelha - como elemento da força simbólica exercida pela presença de pelos naturais, os quais garantem a "naturalidade" identitária do homem e se distanciariam da fragilidade gerada pela modificação dos pelos, os quais seriam para o usuário caracteres típicos de homossexuais efeminados. Somado a isso, a utilização do qualificativo "natural" ratifica a defesa da composição corporal biológica do indivíduo, composta por aspectos lineares fisiológicos e semelhantes à identidade do enunciador.

Ao condenar componentes físicos (musculatura e pelos) e comportamentais (passividade) indicadores da feminilidade em interações públicas, o usuário defende a discrição como recurso performativo-discursivo de preservação da masculinidade pública, inibindo a manifestação de traços considerados femininos, um tipo de instrumento para efetivação do cálculo dos componentes identitários. Porém, no nível da coesão textual, o usuário sinaliza a dificuldade de instalação contínua desse método, ou seja, a dificuldade de discrição da feminilidade e impostação da masculinidade masculinizada, enfatizando a eficácia parcial das práticas mobilizadas para inibição pública e a natureza ontológica de deslizes nas interações sociais. Desse modo, Cafajeste resume sua performance pública em "média", pois, segundo ele, "não [sou] um robô (...) Sou um gay na minha", ratificando, com o uso do termo "médio", o enquadre equivalente no sistema gradual desenvolvido tanto para si próprio como para o parceiro-em-potencial.

O uso da expressão "sou um gay na minha" pode ser questionado sobre várias perspectivas: o que significa essa expressão no cotidiano? Quais os parâmetros para enquadrar-se nessa "categoria"? A fundamentação ideológica dessa categoria resgata quais sentidos para a identidade homoerótica? Sobre o significado, a expressão remete à inscrição de uma posição reservada do usuário a sinalização da sexualidade, procedimento nutrido pela discriminação das possibilidades entre público e privado, feminino e masculinizado, enfatizando o cuidado para a inexpressão de elementos corporais efeminados.

A ausência da manifestação de elementos da feminilidade/passividade nos conduz ao modo de construção dos sentidos do homoerotismo masculinizado, estabelecidos na experiência do informante. Suas vivências são norteadas, em um nível macroestrutual, por um aparato histórico no qual ocorre a valorização da masculinidade e da masculinização, bem como o automático decréscimo do valor simbólico da feminilidade. No nível microestrutural, esse aparato materializa-se em diferentes práticas sociais (ou a ausência delas), coagindo o sujeito para a defesa da masculinização como único modelo de inscrição da dignidade e 
cidadania públicas. Nesse sentido, a ideologia sobre masculinidade, feminilidade e homoerotismo relaciona-se com o cotidiano (off-line) do usuário por meio de outras duas práticas discursivas: os gêneros cotidianos de interação no bairro da Cabanagem e na esfera de trabalho ${ }^{17}$.

Sobre as experiências no bairro, o usuário destaca "ninguém me conhece", o que permite inferir a inexpressão do homoerotismo, por um lado, e a visibilidade da masculinização como expectativa social por outro, construído a partir de uma postura "fechada, séria e calada", o que, na visão do usuário, não se vincula a cultura do bairro, mas a uma seleção particular. Em conjunto, o ambiente de trabalho exerce força motriz em direção ao discurso de masculinização, pois, mediante a experiência das políticas empresariais, as situações de acessibilidade pela masculinização são interpretadas como premiações sociais ("sempre me respeitaram, chamavam para jantares"), quando, na verdade, são condicionantes para manutenção do modelo linear de identidade.

As situações interacionais no bairro e no ambiente de trabalho podem ser compreendidas como práticas discursivas que incidem nas performances online. Todavia, a incidência, sob a perspectiva de Orlandi (2007), ocorre a partir do conceito de silêncio ${ }^{18}$ como forma de construção de sentidos, pois a ausência de determinadas significações (ou forma de manifestação do homoerotismo), mediadas por eventos comunicativos, também remetem ao exercício de apagamento das possibilidades de construção identitária, pois o reconhecimento da validade de determinados sentidos pelos sujeitos é o que conduz a verificação das identidades válidas. No caso do informante, norteados pelo princípio da feminilidade/passividade, o apagamento do homoerotismo conduz a restrição de exercício e ênfase sobre os significados dignificantes acerca das práticas homoeróticas, forjando sua inexistência tanto no âmbito público como privado.

Sobre a estruturação textual, optamos pela restrição ao discurso da área de descrição pessoal, onde se destaca, em primeiro lugar, o reconhecimento do paradigma identitário e seu descumprimento, bem como a exposição de outras diferenças (versatilidade) para compensar o tangenciamento imagético. Em terceiro, delimitou-se as ações do parceiro-em-potencial, de envio de fotos no início da conversa, como estratégia de verificação da feminilidade ou masculinidade masculinizada latentes.

\footnotetext{
${ }^{17}$ Ao considerar o deslocamento multidimensional imposto, este não foi um momento histórico efetivo em sua completude, mas um procedimento que, a todo momento, precisa ser reafirmado, seja pelos aparelhos repressivos físicos ou pelos ideológicos, na linguagem de Althusser (1985).

${ }^{18}$ De acordo com Orlandi (2007, p. 11), "as palavras transpiram silêncio", pois o silêncio atravessa as palavras, se manifesta por meio das palavras e estas, ao mesmo tempo, produzem o silêncio e silenciam outros sentidos.
} 
$\mathrm{Na}$ dimensão da prática discursiva, os valores e sentidos sobre a sexualidade, na publicidade e na privacidade, on-line e off-line, são norteados pelas situações hegemônicas e pelo movimento histórico dos sentidos sobre o homoerotismo masculino. A produção do discurso e, sobretudo, dos desejos, revela o condicionamento e o deslocamento dos sujeitos para o Grindr como espaço simultâneo de libertação e adequação ao regime comportamental público, caracterizados na requisição de identidades masculinizadas por meio de porte físico, posição sexual, etc., como primeiras necessidades do enunciador. Para o consumo, os discursos inscritos pressupõem um modo de interpretação no qual o interlocutor deve distinguir as auto-qualificações de "Cafajeste", o regime gradual das performances como requisitos para interação e relacionamento. Todavia, o alcance dos sentidos depende da distribuição, da circulação do usuário por diferentes espaços virtuais e geográficos, que, neste caso, é a cidade de Belém.

No ínterim destes processos, o interdiscurso ocupa papel central para a projeção da força dos enunciados e da coerência do discurso. Considerando que o interdiscurso, nas palavras de Orlandi (2007), é o "lugar" onde os sentidos são inscritos historicamente e praticados culturalmente, em um regime de movimento entre diferentes formações discursivas, os sentidos sobre homoerotismo, nas performances discursivas de "Cafajeste", inscrevem o movimento entre os valores hegemônicos (masculinidade e feminilidade) e os valores alternativos ou graduais, de (des)cumprimento de requisitos da masculinização, procedimentos sustentados pela experiência da instabilidade e, ao mesmo tempo, da compressão de diferentes práticas sociais sobre a masculinidade, na geração de acessibilidades.

Resgata-se por meio da interdiscursividade o terceiro elemento da análise tridimensional - o da prática social, em que o usuário "Cafajeste" mostra-se pressionado por duas orientações ${ }^{19}$ : de um lado, a ideologia sobre a masculinidade como nobreza ${ }^{20}$, como bem simbólico no jogo de acessibilidades identitárias e sociais, destituindo qualquer conotação positiva sobre a ideia de feminilidade e incutindo a ação da discrição como metodologia de contenção pública; do outro lado, norteadas pelo parâmetro econômico e cultural, as experiências no bairro da Cabanagem e as condições de trabalho promovem o silenciamento do homoerotismo efeminado, como inexistente, um não-dito, o que pode ser nutrido também

\footnotetext{
${ }^{19}$ Consideramos aqui as duas orientações latentes, sem defender, contudo, a inexistência das outras. Na verdade, para esse momento, as forças sociais mostrada com maior força motriz sobre a masculinização do homoerotismo foram estas, priorizando-as.

${ }^{20}$ Bourdieu (2012).
} 
pelos altos índices de criminalidade ${ }^{21}$ e pela dependência ao centro econômico da chamada "Nova Belém"22 com a imagem de trabalhador ideal.

Em síntese, "Cafajeste" compreende a masculinidade como forma de garantia do desejo sexual, de preservação das acessibilidades e de desvio das retaliações sociais, bem como entende a discrição como um método para silenciar, publicamente, qualquer manifestação de feminilidade. Embora persista em uma equação para o equilíbrio, o usuário enfrenta certa dificuldade de regulação performativa, materializada pela articulação das diferenças identitárias (corporais, de posição sexual), entre os valores simbólicos e os papéis sociais desempenhados entre as atividades públicas e privadas. Como estratégia complementar, o usuário promulga a masculinidade e/ou discrição como requisitos para o parceiro-em-potencial, mesmo não as realizando de modo completo, ressaltando que o requerimento para o parceiro funciona como uma extensão reguladora das performances masculinizadas do enunciador para inexpressão de deslizes efeminados em público.

O exercício da debilidade performativa é efeito da interdiscursividade ao restringir as formas de significação e constituição da identidade no ambiente de trabalho e das interações no bairro da Cabanagem, a qual condiciona a manipulação do modelo comportamental aparentemente natural e produto de uma escolha individual. Como resultado, circula, nas interações online do Grindr, uma imagem apriorística do homoerotismo do "machão", o qual é reduzido a uma interpretação homogênea da identidade, como produtor da lineariedade, quando, na verdade, é efeito e ratificador da linearidade, pautada na heterossexualidade aparente.

\section{Gui a fim}

O segundo usuário, "Gui a fim", apresenta-se, em nível vocabular, como "exclusivo", adjetivo que exerce a função de sintetizador dos elementos corporais e imagéticos articulados nas performances on-line e off-line, destacando, por meio das categorias de enquadramento fornecidas pelo aplicativo, sua altura $(1,77 \mathrm{~m})$, seu peso (67 quilos) e a definição de tônus

\footnotetext{
${ }^{21}$ Para maiores detalhes sobre os índices de violência na cidade de Belém, ver: WAISELFISZ, Julio Jacobo. Mapa da violência 2016: homicídios por arma de fogo no Brasil. São Paulo: FLACSO Brasil, 2015.

${ }^{22}$ Mediante a leitura de Lima et al. (2014), compreendemos como a "Nova Belém" o conglomerado de empreendimentos econômicos deslocados para a região da avenida Augusto Montenegro, gerado pela superlotação das região primárias da cidade de Belém, impulsionando a construção de escolas, shoppings, supermercados, entre outros estabelecimentos e destacando o deslocamento do valor simbólico das moradias e das práticas sociais para a extensão entre a avenida Almirante Barroso e o distrito de Icoaraci.
} 
muscular como "torneado". Essas caracterizações conduzem a efeitos de sentido pelos quais se compreende o reconhecimento do usuário ao paradigma imagético-corporal da heterossexualidade aparente, bem como conduz a percepção a racionalidade físicocomportamental de "Gui a fim” sobre o parceiro-em-potencial. Nesse sentido, há a distinção dos elementos tipológicos necessários para um sujeito ter relações com "Gui a fim”, sendo distinguidos em três grupos "gordos, [...] gordinhos [e] afeminados", os quais, performaticamente, representam sujeitos homoeróticos condenados e aceitáveis para as relações públicas.

No caso do par gordo/gordinho, a utilização do diminutivo (no adjetivo gordo) inscreve a diferenciação entre o sujeito acima do peso, dissidente ao ideário de masculinização, e o indivíduo que, embora destoe, pode ser enquadrado no biofísico similar a ideia de "forte" ou "fortinho". Neste caso, a repercussão da dissidência corporal-performática é amenizada em decorrência da aparência de obtenção de um porte másculo e muscular, aproximando-se da ideia de corpo ideal para a publicidade. Porém, essa diferença não é verificável sobre a feminilidade, pois esta é inserida em um retrato dicotômico de (in)existência, entre público e privado, rechaçando, na perspectiva do usuário, qualquer tipo de abertura performática em relações públicas.

Gramaticalmente, ao descrever componentes conformadores da feminilidade, o usuário arrola, de maneira genérica, o "jeito delicado e traços femininos". Mediante esses, "Gui a fim" distingue dois modelos de exercício do homoerotismo masculino: os sujeitos homoeróticos masculinos efeminados e os sujeitos homoeróticos masculinos exagerados: sobre o primeiro grupo, inscrito sob o signo do efeminamento, são identificados pela declaração pública de seu homoerotismo, conhecidos como "assumidos", mas que, não necessariamente, constroem sua identidade sexual sem perpetrar traços femininos, que os conduzisse a ideia coletiva heterossexual do desejo de "ser mulher". Por outro lado, coexiste o grupo identificado pela classificação "exagerados", composto por sujeitos que, na ótica do informante, exacerbam os traços de feminilidade, equiparando-se, aos olhos de outrem (heterossexual), a noção de mulher.

Na divisão grupal, "Gui a fim" sinaliza seu enquadramento no grupo dos sujeitos efeminados, afirmando "gostar da mesma posição que eles [os passivos] gostam". Esse critério ressalta, em primeiro plano, a assunção da sexualidade publicamente e, em segundo, a correlação entre feminilidade, passividade sexual e relações privadas. Nesse sentido, o procedimento para estabilização da masculinização encontra-se entremeado, na percepção do informante, pela dualidade performativa de ser passivo e efeminado na privacidade e, ao 
Júlia Antônia Maués Corrêa; Marcos da Silva Cruz. Entre machos e discretos: discursos, identidades homoeróticas masculinas $\mathrm{e}(\mathrm{m})$ aplicativos de relacionamento

mesmo tempo, a aparência de masculinidade (na verdade, masculinização) e a atividade sexual. Porém, a fim de tornar menos complexa as articulações, o usuário informa, por meio das categorias de pertencimento, ser "versátil passivo", o que, além dos sentidos sobre a ampliação das possibilidades durante o ato sexual, indexa a uma metodologia de determinação da feminilidade/passividade e masculinidade/atividade aos seus respectivos domínios.

A fronteira entre as categorias do homoerotismo masculino apresentadas pelo usuário são delimitadas, portanto, entre público e privado, inscrevendo os usuários "exagerados" em um lugar condenável por "acaba[rem] não se dando ao respeito". O nível gramatical traz a tona uma compreensão singular acerca da discriminação identitária: o conceito de respeito apresenta-se em uma relação de máximas, de um lado seu cumprimento como sujeito efeminado e, do outro, seu descumprimento com o homoerótico exagerado, acarretando a este retaliações físicas e simbólicas, entre os pares homoeróticos e também com a sociedade heterossexual. No plano morfossintático, ao questionar os referentes (atuantes) em relação à noção de respeito, confirmamos que (des)cumprimento é tributário do modelo linear de identidade, matizado sobre o ideal de masculinidade masculinizada, aos ditames heterossexistas.

De maneira situada, a centralidade da noção de respeito é construída por esferas discursivas específicas verificadas como marcantes nas experiências de "Gui a fim": as interações no bairro da Cabanagem, periferia belenense, e o ambiente de trabalho. Nas relações da comunidade periférica, um caso emblemático para informante envolve o acontecimento de uma postura homofóbica em uma festa (direcionada ao público heterossexual) ${ }^{23}$ contra seu amigo. No encerramento do evento, o amigo de "Gui a fim" foi categorizado como viado, em conotação pejorativa, por outro brincante, impulsionando "Gui a fim" a defender o amigo ao argumentar que "cada um é tratado da forma que quer ser".

A argumentação de "Gui a fim" configura-se, de certo modo ambígua, pois encaminha a dois tipos de interpretação sobre a visão do homoerotismo de seu amigo. A primeira, pela articulação "cada um é tratado da forma", insere o amigo em uma relação de recepção da ação de alguém, de uma forma de tratamento, pressupondo um papel de passividade. Contudo, esta é decorrente da responsabilidade do indivíduo atacado, pois ele "[...] quer ser", ou seja, performar sua sexualidade de determinada maneira, reconhecendo a implicações de seus atos nas reações de outrem em atividades cotidianas. Portanto, na ótica de "Gui a fim", a

\footnotetext{
${ }^{23}$ A diferenciação entre festa para o público heterossexual e homossexual reside sobre as vestimentas, o comportamento, a expressão de relações afetivas e/ou amorosas, as músicas tocadas, entre outros elementos. No caso belenense, há territórios específicos para esse tipo de acontecimento festivo, localizados, em sua maioria, no centro da capital (bairro como Nazaré e Reduto), voltada para um público de classe média-alta.
} 
Júlia Antônia Maués Corrêa; Marcos da Silva Cruz. Entre machos e discretos: discursos, identidades homoeróticas masculinas $\mathrm{e}(\mathrm{m})$ aplicativos de relacionamento

manifestação da sexualidade exagerada (seguindo a classificação do informante) é produto da individualidade do sujeito, devendo este arcar com os débitos nas práticas sociais diárias.

Ao mesmo tempo, os enunciados conduzem a uma segunda leitura: a incidência semântica sobre o termo "viado", ao ser utilizado por indivíduos homoeróticos ou por tornarse um tipo de vocativo nas interações entre os sujeitos heterossexuais, esvazia-se, em certa medida, de sentido pejorativo ao destacar a escolha pela dissidência a norma de masculinização, sem, contudo, apagar o fundamento condenatório sobre a inscrição de traços da feminilidade. A ambiguidade do enunciado sinaliza a movência das fronteiras entre os sentidos, as quais, por conta do objetivo da pesquisa, não foram objeto de aprofundamento.

A segunda experiência do usuário nos conduz ao ambiente de trabalho, um empreendimento educacional, onde o informante vivenciou a situação na qual o pai de um aluno exigiu o afastamento do funcionário, motivado pela questão da orientação sexual. A solução da escola foi o esclarecimento para o responsável do aluno que mudá-lo de estabelecimento apenas iria ratificar as práticas preconceituosas, fazendo o pai recuar em sua postura. Mas o que nos interessa é a percepção do usuário sobre os procedimentos de controle da sexualidade e manutenção da masculinização, pois, segundo o usuário, "o que fazemos fora do trabalho não interfere no ambiente de trabalho. A não ser o preconceito que consome os de fora". Essa visão ilustra a potencialidade da ideologia heterossexista na formação cognitiva dos indivíduos, pois, como concordância geral nos estudos do discurso (ORLANDI, 2007; MAINGUENEAU, 2015; VOLOSHINOV [BAKHTIN], 2018; FAIRCLOUGH, 2001), o funcionamento da ideologia ocorre pela estabilização e apagamento simultâneos.

Sobre a estrutura textual, o perfil do usuário apresenta-nos, respectivamente, o objetivo de realização de prazeres sexuais, a delimitação da preferência pela passividade nas relações sexuais (embora, em alguns casos, exerça o papel de ativo), o reconhecimento de posturas dos pares em querer ou não concretizar uma relação sexual e, por último, a enumeração dos caracteres identitários que devem ser efetivados pelo parceiro-em-potencial. Depreendemos sobre a articulação das diferenças identitárias que o usuário reconhece sua localização debilitada, motivada pela inscrição de um entrelugar, entre as práticas na privacidade (feminilidade e passividade) e a publicidade (masculinizada), conduzindo-o a projetar no possível parceiro performances complementares de masculinização a fim de preservar as acessibilidades públicas.

No âmbito da prática discursiva, "Gui a fim" assinala os sentidos sobre o homoerotismo baseado em referências hegemônicas e, simultaneamente, pelas oscilações de sentido por sua localização no entrelugar. Desse modo, a produção do discurso pauta-se, 
historicamente, na crença sobre a inferioridade simbólica da feminilidade, o papel da masculinidade como nobreza, aspectos motivados pela suposição do distanciamento entre as práticas on-line e as atividades off-line, repercutindo na defesa da masculinização como ação de cunho subjetivo. Ao mesmo tempo, a linearidade contemporânea da sexualidade aparente é rompida na medida em que o entrelugar promove a possibilidade de apresentação inconsciente de "traços femininos" na publicidade.

No contexto de entremeagem identitária, o consumo do discurso do informante prescinde por parte dos pares homoeróticos a percepção das delimitações performáticas como requisito para a estabilização dos elementos dos traços identitários em seus respectivos âmbitos, o cumprimento dos requisitos e seu exercício constante. A reverberação do discurso, assim como "Cafajeste", depende da circulação do usuário pelos diferentes espaços geográficos, a fim de aumentar as possibilidades de encontrar parceiros que concordem com o acordo performativo sinalizado.

Embebido na tríade produção-consumo-distribuição, o interdiscurso funciona como base para o regaste histórico dos processos de significação da identidade homoerótica (cf. Seção 2), bem como dos processos de subjetivação por meio do discurso conhecido como heteronormativo. A historicidade garante a força aos enunciados de "Gui a fimm" em direção ao convencimento sobre as acessibilidades com o exercício da masculinização pública e da inibição do desejo sexual homoerótico a esfera das relações privadas, aparentando certo tom de naturalidade à coerência entre a feminilidade como descrédito e a masculinidade masculinizada como acréscimo a identidade homoerótica pública. Essa "coloração natural" é resgatada, ratificada e ampliada por meio do jogo de aparências nas interações no bairro da Cabanagem e no ambiente de trabalho, as quais convergem para a prática no aplicativo.

No terceiro nível da análise tridimensional, da prática social, a ideologia é percebida mediante a unilateralidade de sentidos sobre a feminilidade, a masculinidade e o homoerotismo, lapidando, em sentido negativo, as possibilidades de identificação dos sujeitos e exercendo o controle dos corpos por meio do silenciamento de outras possibilidades de identificação. Essa estratégia restringe a racionalidade do sujeito à crença sobre a unidade e naturalidade da divisão masculinidade/atividade aparente pública e feminilidade/passividade privadas, mesmo que o sujeito seja assumido publicamente. Como já sinalizado, os contextos de situacionalidade narrados pelo informante conduzem a hegemonia das relações econômicas e trabalhistas, no empreendimento escolar, e as relações cotidianas com os pares no bairro da Cabanagem, as quais se relacionam por extensão. 
Júlia Antônia Maués Corrêa; Marcos da Silva Cruz. Entre machos e discretos: discursos, identidades homoeróticas masculinas $\mathrm{e}(\mathrm{m})$ aplicativos de relacionamento

Em síntese, para "Gui a fim”, a masculinização do homoerotismo defende a integridade da ideia de homem, pautada na linearidade de gênero em relações públicas, enquanto que os traços femininos são projetados como um tipo de déficit identitário. Contudo, esse déficit também é realizado pelo usuário na medida em que, nas relações privadas, ocupa o papel de passividade sexual, inserindo-o em um entrelugar, que o obriga a regular as performances a fim de ratificar as fronteiras entre público e privado, garantindo as acessibilidades pela heterossexualidade aparente. A aparência e a repetição das performances masculinizadas adquirem potencial suficiente para conduzir ação, racionalidade, subjetividades e, sobretudo, apagar a assunção pública do homoerotismo por meio das trocas simbólicas exercidas em diferentes esferas sociais.

\section{Considerações finais: a porta entreaberta do armário como regularidade identitária}

A relação entre discurso, conhecimento e poder timbra o processo de construção do homoerotismo masculino, projetando-o, a priori, como sodomia ou corrupção do caráter. No contexto pós-moderno, com a organização dos grupos marginalizados e a internet 2.0, houve a ênfase na natureza fragmentada e articulada das identidades e sua composição a partir de um manufaturado discursivo, desestabilizando a lineariedade entre sexo, gênero e sexualidade e implicando a rearticulação das estratégias da sociedade heteronormativa, dentre as quais o deslocamento multidimensional e valorização da masculinização como símbolo de nobreza. Com isso, o resultado remete a ênfase na mudança do eixo de linearidade, ao se abster da somatória entre essência e aparência e adotar a necessidade do jogo de aparências, pela articulação das "paisagens" identitárias, a fim de garantir a preservação física e simbólica.

A historicidade do homoerotismo masculino conduz a compreensão da identidade dos "machões e discretos", de um lado, como homogêneas entre os pares homoeróticos, e, de outro, como abalada pela articulação de diferenças fragmentadas. Nesse sentido, constatamos a complexidade de relações que constituem a imagem do homoerotismo na voz dos machões e buscamos, neste momento, identificar algumas regularidades acerca da identidade vista como heteronormativa.

A ideia de machão como efeito de um abismo identitário. A impressão sobre a identidade dos defensores da masculinização como condição interacional é percebida como a fonte do sistema de desqualificação da feminilidade homoerótica, quando, em um plano mais profundo, é o resultado das dificuldades de articulação e separação das performances 
Júlia Antônia Maués Corrêa; Marcos da Silva Cruz. Entre machos e discretos: discursos, identidades homoeróticas masculinas e(m) aplicativos de relacionamento

identitárias entre o âmbito público e privado, materializada pela debilidade no manuseamento das vestimentas, da estética corporal e do papel sexual desempenhado. Essa debilidade inscreve tanto "Cafajeste" como "Gui a fim" em um entrelugar, motivado por pressuposições da masculinidade heterossexual, as quais não inserem os informantes como heterossexuais ou como homossexuais, mas em um abismo de aparências e debilidades em exercê-las.

Ser passivo é ser efeminado. A pressuposição mais recorrente indica a correlação "natural" entre papéis sexuais e performances específicas que, para os machões, acorrenta os traços de feminilidade ao indivíduo que, em relações sexuais, exerce o papel de passivo. Essa compreensão funda-se na histórica desvalorização das performances de gênero feminino, distinguindo o valor simbólico dos sujeitos e inserindo-os em um enquadro de submissão à normatividade ou de apagamento da dignidade humana.

\section{A comunidade do bairro e do trabalho como pilares de propagação da} masculinização. Ambos os informantes sinalizam a funcionalidade das experiências ou a ausência delas como conformadoras de sentido sobre a masculinização do homoerotismo e da preservação das acessibilidades sociais, pois, de um lado, o receio e a ausência de sinalização da sexualidade no bairro conduzem ao receio de exposição, e as estratégias materializadas pela imagem de funcionário ideal e pelas interações entre os colegas de trabalho, por outro. Esses domínios convergem para a potencialização da "naturalidade" da masculinização como método de vida regido pela ausência de marginalização e desdignificação social e, ao mesmo tempo, são resgatadas como pano de fundo na imperatividade da masculinização.

A relação dialética entre on-line e off-line. Diferente da relação causal, característica da condução multidimensional forçada, o regime constituinte das identidades dos machões é marcado pelo jogo de idas e vindas entre as práticas no aplicativo (on-line) e no bairro e no ambiente de trabalho (off-line), fazendo com que haja, na verdade, sentidos circulantes. Nesse cenário, é possível afirmar que o Grindr ocupa um papel de Medium, ao representar um ponto de convergência e divergência de sentidos, aproximando as dimensões até então distanciadas. Contudo, essas são constatações primárias, as quais precisam de aprofundamento acerca dos limites entre as duas dimensões no exercício das sexualidades e envolvem uma série de outros fatores.

A masculinização como tripla aparência. Com elucidação dessas dimensões e categorias sobre a constituição do homoerotismo masculinizado, evidenciamos o funcionamento de construções discursivas sobre a natureza e valor da masculinidade heterossexual, que, ao ser imposta transforma-se em masculinização, e o exercício debilitado da heterossexualidade aparente como forma de preservação da humanidade. Enquanto 
manufaturados discursivos, as identidades sexuais são representações forjadas sobre a ideia de masculinidade conduzindo a um tipo primeiro de aparência e, por extensão imposta, são constantes tentativas de masculinização do homoerotismo, conformando um tipo secundário de aparência. A terceira dimensão, como produto da segunda, ocorre na medida em que a evidência do homoerotismo expresso publicamente é apagamento por meio da discrição da feminilidade e ênfase na masculinização, estabilizando a ideia de homogeneidade.

\section{Referências}

ALTHUSSER, Louis. Aparelhos ideológicos do Estado: notas sobre aparelhos ideológicos do Estado. Rio de Janeiro: Edições Graal, 1985. Disponível em: $<$ https://politica210.files.wordpress.com/2014/11/althusser-louis-ideologia-e-aparelhosideolc3b3gicos-do-estado.pdf>. Acesso em: 16 mar. 2019.

AUSTIN, John Langshaw. Quando dizer é fazer. Porto Alegre: Artes Médicas, 1990. Disponível em: <https://edisciplinas.usp.br/mod/resource/view.php?id=2395374>. Acesso em: 16 mar. 2019.

BORBA, Rodrigo. Linguística Queer: uma perspectiva pós-identitária para os estudos da linguagem. Entrelinhas, São Leopoldo, RS, v. 9, n. 1, p. 91-107, jan./jul. 2015. Disponível em: <http://revistas.unisinos.br/index.php/entrelinhas/article/viewFile/10378/4862>. Acesso em: 16 mar. 2019.

BOURDIEU, Pierre. A dominação masculina. Tradução Maria Helena Kühner. 11 ed. Rio de Janeiro: Berthand Brasil, 2012. Disponível em: <https://edisciplinas.usp.br/pluginfile.php/762315/mod_folder/content/0/BOURDIEU_A\%20 domina\%C3\% A7\%C3\%A3o\%20masculina.pdf?forcedownload=1>. Acesso em: 16 mar. 2019.

BUTLER, Judith. Sujeitos do sexo/gênero/desejo. In: Problemas de gênero: feminismo e subversão da identidade. Rio de Janeiro: Civilização Brasileira, 2003. Cap. 1, p. 17-60. Disponível em: <https://cadernoselivros.files.wordpress.com/2017/04/butlerproblemasdegenero-ocr.pdf>. Acesso em: 16 mar. 2019.

COSTA, Léa Maria Gomes da; BRITO, Lilian Simone Amorin. (Re)ordenamento territorial urbano e segregação socioespacial em Belém. Revistado Instituto Histórico e Geográfico do Pará, IHGP, v. 1, n. 1, p. 13-30, jan./jun. 2014. Disponível em: <http://www.ihgp.net.br/revista/index.php/revista/article/download/2/pdf_1 >. Acesso em: 16 mar. 2019. DOI: https://doi.org/10.17553/2359-0831/ihgp.n1v1p13-30

CHOULIARAKI, Lilie; FAIRCLOUGH, Norman. Discourse in late modernity: rethinking critical discourse analysis. Edinburgh: Edinburgh University Press, 1999.

FAIRCLOUGH, Norman. Discurso e mudança social. Tradução Izabel Magalhâes. Brasília: Editora Universidade de Brasília, 2001. Disponível em: 
<https://www.academia.edu/5281166/Discurso_e_Mudan\%C3\%A7a_Social_-

_Norman_Fairclough>. Acesso em: 16 mar. 2019.

FAPESPA. Mapa de crimes contra a pessoa: ano de 2013. Disponível em: <http://www.fapespa.pa.gov.br/anuario_estatistico/social.html>. Acesso em: 8 dez. 2018.

FOUCAULT, Michel. A história da sexualidade: a vontade de saber. Tradução Maria Thereza da Costa Albuquerque e José Augusto Guilhon Albuquerque. Rio de Janeiro: Edições Graal, $1988 . \quad$ Disponível em: $<$ https://edisciplinas.usp.br/pluginfile.php/2940534/mod_resource/content/1/Hist\%C3\%B3riada-Sexualidade-1-A-Vontade-de-Saber.pdf>. Acesso em: 16 mar. 2019.

HALL, Stuart. A identidade em questão. In: Identidade cultural na pós-modernidade. Tradução Tomaz Tadeu da Silva e Guacira Lopes Louro. 11 ed. Rio de Janeiro: DP\&A, 2006. Disponível em: <https://edisciplinas.usp.br/mod/resource/view.php?id=2220456>. Acesso em: 16 mar. 2019.

LEWIS, Elisabeth Sara. Do "léxico gay" à Linguística Queer: desestabilizando a norma homossexual oculta nas Teorias Queer. Estudos Linguísticos, São Paulo, v. 47, n. 3, 2018, p. 675-690. Disponível em: <https://revistas.gel.org.br/estudos-linguisticos/article/view/2049> . Acesso em: 16 mar. 2019. DOI: https://doi.org/10.21165/el.v47i3.2049

LIMA, José Júlio; SILVA, Raul Ventura; CRUZ, Camila Cristina da Costa S. Modificações recentes na configuração da periferia de Belém do Pará e suas consequências na mobilidade urbana. In: III Encontro da Associação Nacional de Pesquisa e Pós-graduação em Arquitetura e Urbanismo. Anais... São Paulo, 2014, p. 2-14. Disponível em: $<$ https://www.anparq.org.br/dvd-enanparq-3/htm/Artigos/SC/ORAL/SC-HDC-

034_LIMA_SILVA_CRUZ.pdf $>$. Acesso em: 16 mar. 2019.

LOURO, Guacira Lopes. Teoria queer: uma política pós-identitária para a educação, Estudos Feministas, v. 9 , n. 2, p. 541-553, 2001. Disponível em: <http://www.scielo.br/scielo.php?pid=S0104026X2001000200012\&script=sci_abstract\&tlng=pt $>$. Acesso em: 16 mar. 2019. DOI: https://doi.org/10.1590/S0104-026X2001000200012

MAINGUENEAU, Dominique. Discurso e análise do discurso. São Paulo: Parábola Editorial, 2015.

MOITA-LOPES, Luiz Paulo. Lingüística Aplicada e vida contemporânea: problematização dos constructos que têm orientado a pesquisa. In: Por uma Linguística Aplicada Indisciplinar. São Paulo: Parábola, 2006. Cap. 3, p. 85-107.

MOITA-LOPES, Luiz Paulo. Identidades Fragmentadas: a construção discursiva de raça, gênero e sexualidade em sala de aula. Campina, SP: Mercado de Letras, 2002.

MISKOLCI, Richard. Desejos digitais: uma análise sociológica da busca por parceiro online. Belo Horizonte, MG: Autêntica Editora, 2017.

ORLANDI, Eni Puccinelli. As formas de silêncio: no movimento dos sentidos. 6 ed. Campinas: Editora da Unicamp, 2007. Disponível em: <https://www.docsity.com/pt/as- 
formas-do-silencio-eni-orlandi/4882612/>. Acesso em: 16 mar. 2019. DOI: https://doi.org/10.7476/9788526814707

PERLONGHER, Néstor. O negócio do michê: a prostituição viril em São Paulo. São Paulo: Editora Brasiliense, 1987. Disponível em: <https://moodle.ufsc.br/pluginfile.php/1058034/mod_folder/content/0/PERLONGHER\%2C\% 20Nestor.\%20O\%20neg\%C3\%B3cio\%20do\%20Mich\%C3\%AA\%20\%5Blivro\%20completo $\% 5$ D.pdf?forcedownload=1>. Acesso em: 16 mar. 2019.

REIS, Ramon. Concurso Marquinha de Biquíni: visibilidades político-corporais entre jovens homossexuais em um bairro "periférico" de Belém. Bagoas, Natal, v. 7, n. 13, 2015, p. 323351. Disponível em: <https://periodicos.ufrn.br/bagoas/article/view/9661>. Acesso em: 16 mar. 2019.

SANTOS, Boaventura de Souza. Para uma sociologia das ausências e uma sociologia das ausências. In: Conhecimento prudente para uma vida decente: um discurso sobre as ciências revisitado. São Paulo: Cortez, 2004. Cap. 34, p. 777-821. Disponível em: <https://www.academia.edu/7823135/97023395-SANTOS-Boaventura-de-Souza-OrgConhecimento-Prudente-Para-Uma-Vida-Decente>. Acesso em: 16 mar. 2019.

SANTOS FILHO, Ismar Inácio dos. A construção discursiva de masculinidades bissexuais: um estudo em linguística queer. 2012. 248 f. Tese (Doutorado em Linguística) Universidade Federal de Pernambuco, Recife, 2012. Disponível em: <https://repositorio.ufpe.br/handle/123456789/11663>. Acesso em: 16 mar. 2019.

SEDWICK, Eve Kosofsky. A epistemologia do armário. Cadernos Pagu, Campinas, SP, v. 28, n. 1, p. 19-54, jan./jun. 2007. Disponível em: <https://periodicos.sbu.unicamp.br/ojs/index.php/cadpagu/article/view/8644794>. Acesso em: 16 mar. 2019. DOI: https://doi.org/10.1590/S0104-83332007000100003

SCOTT, Joan W. A invisibilidade da experiência. Proj. História, Revista do Programa de Estudo Pós-Graduados em História, São Paulo, v. 16, n. 1, fev. 1998. Disponível em: <https://revistas.pucsp.br/index.php/revph/article/view/11183>. Acesso em: 16 mar. 2019.

SITE DO GRINDR. Disponível em: <https://www.grindr.com/br/about/>. Acesso em: 2 out. 2018.

SPARGO, Tasmin. Foucault e a teoria queer. Belo Horizonte, MG: Autêntica Editora, 2017.

TRINDADE JR., Saint-Claire C. A natureza da urbanização na Amazônia e sua expressão metropolitana. Geografares, Vitória, v. 1, n. 1, jun. 2000. Disponível em: <http://www.portaldepublicacoes.ufes.br/geografares/article/download/1169/881>. Acesso em: 16 mar. 2019.

TRINDADE JR., Saint-Claire C. Fronteira urbana-imobiliária e a dinâmica metropolitana na Amazônia brasileira. In: VIII Encuentro dos Geografos da America Latina. Anais... Santiago: Universidad de Chile, v. 1, n.1, 2001, p. 51-71. DOI: https://doi.org/10.7147/GEO1.1169

VAN DIJK, Teun A. Discurso e manipulação. In: Discurso e poder. São Paulo: Contexto, 2008. Cap. 8, p. 233-263. 
Júlia Antônia Maués Corrêa; Marcos da Silva Cruz. Entre machos e discretos: discursos, identidades homoeróticas masculinas $\mathrm{e}(\mathrm{m})$ aplicativos de relacionamento

VOLOSHINOV, Valentin. Marxismo e filosofia da linguagem: problemas fundamentais do método sociológico na ciência da linguagem. 2 ed. São Paulo: Editora 34, 2018.

Recebido em: 15 de agosto de 2019

Aceito em: 19 de novembro de 2019 